\title{
Mobile Assisted Language Learning: Evidence of an Emerging Paradigm Nabil MORCHID
}

\author{
Laboratory of Language and Society, Ibn Tofail University, Morocco
}

Email: nab.morchid@gmail.com

\begin{abstract}
Mobile-Assisted Language Learning (MALL) may not have reached the highest levels of maturity; still, it manages to forge an identity of its own in the educational sphere. The intent of this paper is to substantiate the legitimacy of MALL. In particular, this study adopts a content-design approach as a means of researching the reciprocity between the offerings of mobile technology and the imperatives of language learning. The content-design estimation of the different extensions of MALL revealed the multiple affordances of mobile technology in the language learning discourse. Short Message Service (SMS)-based language learning, educational podcasting, mobile social networking, and game-based learning emphasise the potential of mobile technology in a wide range of language learning contexts. Still, for MALL to reach its full potential, it must belong dependently of a valid theoretical and pedagogical orientation in language learning.

Keywords-education, ICT, mobile learning, MALL, social media.
\end{abstract}

\section{INTRODUCTION}

MALL is an offspring of computer-assisted language learning (Kukulska-hulme, 2012). There is more to MALL than the normal progression from the core patterns of its predecessor. The mobile trend in language learning manages to develop an identity of its own in the educational field by reinventing the environments needed for language learning. MALL favours a learner-centred approach to language learning in which the continuity and spontaneity of use are the key features (Kukulska-hulme, 2009).

MALL has multiple manifestations in the educational discourse, and so are the perspectives used in labelling the mobile tradition in language learning. Kukulska-hulme and Shield (2008) adopts a content- design approach in determining the multiple incorporations of mobile technology for language learning purposes. A content approach to MALL synchronises with the basics of institutionalised education while a design approach to MALL emphasises the autonomy of learners who can be functional in contexts other than school. In parallel, Miangah and Nazarat (2012) forwards a language-skill taxonomy to determine the impact MALL has on distinct language learning skills. Yang (2013) advances a classification of MALL that is centred on the internal capabilities of mobile devices. For the purpose of this study, a content-design approach is used in estimating the potential of MALL. In particular, different incorporations of MALL are exposed and researched for their added values.

\section{SMS-BASED LANGUAGE LEARNING}

SMS is arguably the most prevalent form of wireless data exchange in view of its availability in a wide range of mobile devices regardless of their levels of sophistication. The key feature of SMS resides in its ability to assist wireless connectivity in the absence of Internet coverage. Indeed, SMS-based learning is well suited to the basics of MALL because of the convenience of accessibility and affordability. A of research has been conducted with the intent to experiment on the use of SMS in language learning.

Motiwalla (2007) enquires on the use of SMS and Wireless Access Protocols (WAP) text-messaging to extend learners' abilities to learn outside the traditional school environments. The experimentation is held on a population of higher education learners who are brought to interact on an m-learning platform by means of textmessaging. The study is not specific to the influence of SMS and WAP text-messaging on language learning per se; still, it does not exclude course contents that are exclusive to language learning. The findings from the research corroborate the legitimacy of the m-learning treatment. Most importantly, the study demonstrates the ability of mobile technology to assist language leaning from the perspective of SMS and WAP text-messaging.

Cavus and Ibrahim (2009) is presented with the intent to explore the susceptibility of SMS text-messaging to enhance learners' ability to learn technical English vocabulary. The enquiry is held on a population of 45 firstyear undergraduate students. The subjects are allowed 
permanent access to mobile phones that support SMS messages. At regular intervals of time, the subjects receive SMS messages which display a selection vocabulary input. The findings from the research enquiry reveal the convenience of SMS text-messaging in a distinct language learning environment. Also, the study gives evidence of positive attitude towards the use of mobile learning on the part of learners who show willingness to engage in further learning experiences that are enhanced by mobile technology.

Zhang, Song and Burston (2011) manages to demonstrate the advantages of a mobile-assisted language approach to vocabulary learning by means of SMS connectivity. The research findings corroborate the advantages of the SMS-based approach to vocabulary learning. The use of SMS text-messaging in vocabulary learning is understood to boost learners' use of "fragmented time" and thereby increase the odds for retention (Zhang, Song and Burston, 2011, p.208). Also, learners' reliance on their mobile phones conditions regular exposure to vocabulary input, which positively impacts the vocabulary learning process.

Plana, Torrano and Grova (2012) interrogates the effectiveness of an SMS-based instructional tool in the teaching of English as a foreign language. The study is carried out on a population of 13 first-year university students over a two-year period. The duration of the enquiry is chronologically structured to answer four research questions:

Is using SMS messaging via a mobile phone an effective tool in terms of motivation and engagement? (2) What types of mini-lessons do subjects think are better to be sent via SMS in terms of effectiveness, engagement and usefulness for their learning purposes? (3) What is the appropriate time for the activities to be sent? (4) Did students who participated in the project perform better that the control groups? (Plana, Torrano and Grova, 2012, p. 33)

The findings from the research enquiry corroborate the hypothesised advantages in the use of SMS-based technology in language learning. As for learners' attitudes towards the experimental tool of learning, the large majority of the participants approve off the SMS-based tradition in language learning. Still, they favour less complex SMS exercises that are completed in relatively shorter time than is the case with difficult exercises. Also, the most suitable time period for the subject to receive the SMS exercises is reportedly from $1 \mathrm{pm}$ to $8 \mathrm{pm}$. Concerning the content based part of the study, there is evidence of the outperformance of the experimental group in the post-tests.

SMS-based language learning measures up to a sustainable trend in educational technology because it synchronises with the fundamentals of language learning. The features of connectivity, mobility and affordability within the SMS based model of learning positively impact the environments needed for language learning. Most importantly, SMS-text messaging does not only extend learners' abilities to access course content or language input for the sake of linguistic proficiency, but it yields new opportunities for a different kind of learning that it is empowered from the inside. Learners are brought to take control of their own learning in environments of much authenticity that are true to their needs.

\section{EDUCATIONAL PODCASTING}

Podcasting is a polyvalent medium of communication because of its ability to diffuse multiple digital file formats. Podcasting does not only revolutionise the distinctions between the conventional channels of communication, but it also causes the proliferation of varied digital media contents. Most importantly, the increasing availability and affordability of portable devices ensure welcoming environments for further expansion of podcasts. Sophistication is the key feature of this relatively new trend in communication and it is well suited to the orientations needed in the academic discourse to reach better performance standards. The impact of educational podcasts on language learning is well observed from the lens of many experimental studies.

Abdous, Camarena and Facer (2015) exposes the most convenient applications of podcasts in foreign language learning. In particular, the study contrasts the instructional use of podcast technology to a supplemental use of the same technology. An operational definition is given for each of the two incorporations of educational podcasting. Supplemental podcasting designates the unplanned use of podcasting, in which faculty members provide students with recorded lectures for later use and review while integrated podcasting targets the incorporation of "podcasting into a variety of instructional activities, which includes recorded critiques of student projects and exams, student video presentations, student interviews, recorded lectures, dictations, roundtable discussions, and guest lecturers" ( Abdous, Camarena and Facer, 2015, p. 79). The experimental study is carried out on 128 students distributed over eight foreign language learning classes, in which the courses are taught in English, German, Spanish, Japanese and French. A pretest-posttest design is adopted to measure the impact of the two incorporations of 
podcasting on learners' performance standards. The findings from the research enquiry corroborate the hypothesised advantages of an instructional incorporation of podcasting in language learning in comparison with the supplemental use of the same technology. The advantages of the instructional use of podcasts translate into increased willingness among students to use the technology, enhanced ease in the completion of school assignment and improved speaking skills. Indeed, the study does not only substantiate the legitimacy of podcasting as a significant instructional tool in language learning, but it enables new configurations of podcasting for educational purposes.

Farangi, Nejadghanbar, Askary, and Ghobrani (2015) reports on the influence of podcasting on learners' speaking skills. In particular, this experimental research is held on 60 Iranian EFL learners who are presented with an upper-intermediate level of English. The participants fall within the same age category, 15-18 year olds, and are all male learners. The gender bias in the research sample is attributed to the concentration ratio of the mobile phone technology that is favourable to males more than females in Iran. The participants are arbitrarily distributed over three groups of 20 learners, one control group and two experimental groups. The control group is taught in a traditional way. The first experimental group receives a student-centred incorporation of educational podcasting, in which the learners create and react to their own podcasts on a web-based platform that is monitored by the instructor. In the second experimental group, a teachercentred approach to learning is adopted. The learners are required to access a selection of podcasts that is fully developed by the instructors. A pretest-posttest design is used to compare the performances of the three groups. Eventually, the findings from the study substantiate the advantages from using educational podcasts as a means to boost EFL learners' speaking skills. The learners in both experimental groups outperform their peers in the control group in view of their recently enhanced speaking abilities. The two experimental groups are identified with performance variances. The learner-centred group shows higher performance standards than is the case with the teacher-centred group. On this evidence, the use of podcasts in language learning needs to be part of a socially oriented process where learners are prompted to exchange both attitudes and course contents.

In parallel, Al Quasim and Al Fadda (2013) informs on the impact of the same educational technology on other language-learning skills among a different population of learners. Eventually, the research is carried out on 46 female Saudi EFL learners. All the participants are undergraduate college students with no prior knowledge on how to handle podcasts. The participants are assigned to two groups. The control group encompasses 21 participants who are taught in a conventional way. The experimental group, on the other hand, is made of 25 participants who are offered the means, a mobile phone with Internet connection, to access the podcasts needed for the treatment. In addition to posttest-pretest design, a questionnaire is handed to the experimental group to measure learners' attitudes towards the experimental use of podcasts. Eventually, the post-test scores corroborate the experimental group's outperformance in listening comprehension skills and thereby validate the legitimacy of podcasting in language learning. As for the participants' attitudes towards the use of podcasts, there is evidence of positive attitude towards the merits of the experimental technology mainly because of the opportunities it yields for collaborative learning.

In line with what has been noted on the multiple incorporations of podcasting in language learning, Li (2010) informs on the effects of podcasting on learners' attitudes towards language learning. The experimental study is presented as a mixed-methods case study, initially held on a sample population of 10 Hon Kong secondary ESL students which is subsequently narrowed down to 3 participants. The participants are trained on how to use varied technology devices to access podcasts. In a later stage, the participants are allowed access to a wide selection of Internet accessible podcasts to choose the most suitable contents for language learning. The researcher uses three instruments for data collection: interviews, journal writing and questionnaires. The interview is managed to serve two purposes: to disregard the participants who hold negative views of the intended use of podcasting and to construct a solid view of the three participants' attitudes towards podcasting. The journal is used to keep track of the changes in learners' attitudes towards podcasting. The questionnaire is managed to yield quantifiable data specific to learners' appreciation of the experimental treatment. The findings from the study validate the hypothesised influence of podcasting on language learning. This influence is well expressed in learners' positive attitudes towards educational podcasts. Podcasting does not only enhance learners' listening and speaking skills but it also increases the affect variable in language learning. In this vein, a participant reports: "I enjoy listening to the culture of the US. It is fun to learn things this way." ( $\mathrm{Li}, 2010$, p. 85). Still, the incorporation of educational podcasts in language learning is presented with a number of challenges that basically relate to the "style of podcasting" ( $\mathrm{Li}, 2010$, p.87). In this respect, the podcasts used for language learning need to be true to 
learners' interests. The length and format of podcasts are important determinants of use because learners are more inclined to use audio-visual podcast of appropriate lengths than is the case with long audio podcasts.

As noted above, educational podcasting allows itself to be a sustainable tool in language learning. The capabilities of podcasting cause the proliferation of varied language-learning input. Most importantly, the feature of accessibility within pocasting is espoused with high levels of authenticity. Language learners are brought to take control of their own learning. Although there is evidence of the legitimacy of podcasting as a means of instruction in the language learning discourse, more research is needed to optimise the resources for a valid and sustainable incorporation of this mobile trend in language learning. In this respect, as it has been reported by Abdous et al. (2015), the instructional use of podcasting is more advantageous to language when it is planned and contextualised. Research needs to concentrate on the most convenient configurations of podcasting for the technology to synchronise with the basics of formal education. In parallel, more experimental studies are required to interrogate the efficiency of podcasting in improving distinct language learning skills other than listening and speaking, with maximum emphasis on the accuracy dimensions in language learning.

\section{MOBILE SOCIAL NETWORKING}

Social networking is a web-based orientation among a large population of Internet users. Not only does social networking revolutionise access to information, but it also redefines the realities of social life. Kaplan and Haenlein (2010) traces back social networking to the fundamental structures of social media, also referred to as " a group of Internet-based applications that build on the ideological and technological foundations of Web 2.0, and that allow the creation and exchange of user Generated Content" (p.61). Indeed, the social media constitute a virtually rich environment where different platforms constantly evolve to stimulate and enable the exchange of a wide range of contents. Social networking is well positioned to carry in the intent of the social media in view of its susceptibility to endorse the social nature of communication. Social networking applications are optimised to activate massive exchange of information, experience and attitude between the members of different social groups across the globe, locally and globally. The far-reaching character of social networking causes reciprocal effect on the part of its users. Reciprocity is the key feature of social networking, and there should be no reason why it cannot adapt to the fundamentals of language learning. Most importantly, the attributes of social networking are further extended by the principle of mobility in portable devises. In this vein, the use of social networking in MALL yields favourable environments for language learning. In this subsection, the legitimacy of mobile social networking as a means for language learning is examined from the perspective of distinct social networking mobile applications.

\subsection{Facebook}

Facebook is arguably the world's most popular platform for social networking. The Facebook statistics reveal that the average number of daily mobile-Facebook users is 1.15 billion for December, 2016 (Facebook, 2017). Facebook is presented with the convenience of portability which allows it be a functional tool in MALL. Indeed, there is evidence of the massive growth of Facebook which has become a worldwide social network with an increasing number of users. Facebook's content-sharing capabilities are presented with the ability to impact the educational discourse. The legitimacy of Facebook as a suitable learning environment for language learning is captured from the lens of the following studies:

Akbari, Pilot and Simons (2015) uses three variables from the Self-Determination Theory, "autonomy", "competence" and "relatedness", to reveal the differences in foreign-language learning between a an experimental group where learning is carried out on a Facebook page and a control group with no experimental treatment. The experimental study is presented with a pre-test-post-test design and it is carried out on a sample population of 40 doctoral students. The treatment in the experimental group is conducted over a one month period. The participants take part in different language-learning activities on a Facebook page. The language learning activities emphasise learners' interactivity and participation. Meanwhile, the intervention in the control group is conceived to recreate similar learning experiences except for the inclusion of a Facebook page as a learning environment. The research findings corroborate the hypothesised advantages of Facebook-mediated language learning. In particular, all the variables under investigation receive better treatment in the experimental group than is the case in the control group. The participants in the experimental group have the ability to outperform their peers in face-to-face learning environment. This is attributed to the favourable learning environments in social networking, where learners are made more competent, autonomous and susceptible to relate to one another throughout their language-learning experiences. The experimentation gives evidence of the positive influence 
social networking has on language learning when Facebook is used as a medium of instruction.

The potential of Facebook to improve learners' communicative competencies is captured from the lens of Buga, Căpeneaţă, Chirasnel and Popa (2014). The study departs from the extensive use of Facebook as a mass medium of communication to conceive a sustainable educational tool in language learning. The intervention is carried out on a sample population of 50 Romanian foreign-language learners, in which one group is made of 19 middle-school students with English as a foreign language and another group is made of 19 high-school students with French as foreign language. All the participants are brought to connect on Facebook and post different language learning assignments. The teacher monitors learners' contributions. The results of the experimentation indicate high levels of involvement on the part of students who respond positively to the experimental learning activities. The findings from the study reveal the positive influences Facebook has on learners' attitude towards foreign-language learning.

In parallel with what has been noted on the possible incorporations of Facebook as an educational tool in language learning. Lantz-Anderson, Vigmo and Bowen (2013) reports on the impact of Facebook on language learning from a socio-cultural perspective. The emphasis is on the ability of Facebook to generate welcoming environments for language learning with ample opportunities for collaboration. The socio-cultural view of learning is optimised and contained in a cross-cultural exploratory case study, held on a sample population of 60 students from varied socio-cultural contexts. Eventually, the participants in the study are located in Columbia, Finland, Sweden and Taiwan where the English language is not students' native language. Ethnographic data are collected form students' multiple interactions on a Facebook group for the purpose of investigating the use of social networking as a means for academic English language learning. The findings from the research demonstrate the potential of Facebook to complement the institutionalised practices in language learning. The Facebook-mediated learning experience is found advantageous to students because it offers interactive learning environments. Still, the spontaneity of Facebook language learning needs to adapt to the formal character of education as a mass medium of orientation.

Facebook incarnates the fundamentals of social networking. An increasing number of studies are managed to interrogate the legitimacy of Facebook in language learning. The offerings of Facebook in the language learning discourse are consequential; still, its incorporation for educational purposes is not without difficulties. The spontaneity of Facebook needs orientation to adapt to the institutionalised practices in formal education.

\subsection{WHATSAPP MESSENGER}

WhatsApp Messenger is another leading freeware application for cell phones with more than a billion active users all over the world (WhatsApp, 2017). WhatsApp was initially presented as an Internet-based messaging form of data exchange. The internal structures of WhatsApp have rapidly evolved to transform into a consequential social networking service as it "now supports sending and receiving a variety of media: text, photos, videos, documents, and location, as well as voice calls". The WhatsApp platform encapsulates a number of conveniences that are possibly advantageous to the educational discourse and language learning is no exception. In this vein, the offerings of the WhatsApp technology in language learning are captured from the lens of selection of studies that vary the perspectives of experimentation.

Lai (2015) investigates a WhatsApp-based immersion in second-language learning. Language immersion is typical of the use of students' native language as a means of instruction in varied course contents. The study synchronises the immersion principle in language learning with the WhatsApp technology. In particular, the WhatsApp platform is used to ease Hong Kong seventhgrade students' ability to learn high-frequency English verbs. The findings of the study substantiate potential of mobile immersion. The participants' ability to learn vocabulary increases in parallel with their connectivity on WhatsApp. Also, the WhatsApp platform is found adequate for interactive language learning.

In line with what has been noted on the offerings of WhatsApp in language education, a study by Aburezeq (2013) varies the perspective of enquiry by capitalising on teachers' view of what should be a WhatsApp-based model of language learning. Eventually, the study is intended to open up new horizons for the teaching of the Arabic language in the United Arab Emirates. The experimentation is held over a fifteen-week period on a mixed population of pre-service teachers and students for the purpose of estimating the offerings of WhatsApp technology in distinct language learning contexts. Eventually, both teachers and students are brought to take part in customised WhatsApp leaning environments in order to determine the susceptibility of the instructional model to impact three modes of interaction: learnerlearner, learner-content and learner-teacher. The findings of the study corroborate the positive effect of the 
WhatsApp incorporation on the three types of interaction. In this vein, the WhatsApp model of learning is presented with the ability to ease multiple modes of communication in the context of language learning. Still, the incorporation of WhatsApp in language leaning is also obstructed by the scarcity of theoretical frameworks with the ability to inform on the correct use of the technology.

Fattah (2015) is conducted with the intent to investigate the use of WhatsApp to enhance students' writing skills, in particular punctuation and sentence structure. The experimental study is carried out with a prepost-test design on a sample population of $30 \mathrm{EFL}$ students in Saudi Arabia. The treatment in the experimental group consists of engaging students in an interactive writing activity on a WhatsApp group. On a weekly basis, the participants respond to a writing topic throughout five distinct steps: pre-writing, drafting, reviewing, editing, and publishing. Simultaneously, the control group is instructed identical course contents with the exception of the WhatsApp inclusion. The findings of the study substantiate the advantages from the instructional use of WhatsApp in the teaching of writing. The students in the experimental group were able to outperform their peers in the control group because of their enhanced abilities to generate correct sentence structures and punctuate their written compositions

Mobile-assisted language learning is an emerging paradigm in language education and so is the WhatsApp orientation in language learning. The legitimacy of WhatsApp as means of language learning has been validated from many perspectives. The offerings of WhatsApp are of strategic interest to the language learning discourse. They benefit language learners in many ways. Still, for maximum efficiency, the educational incorporation of WhatsApp must synchronise with valid pedagogies and theories of learning.

\subsection{YOUTUBE}

YouTube is definitely the largest video-sharing platform on the Internet with more than a billion users all over the world (Youtube, 2017). The Internet giant is presented with the convenience of mobility as more than half of YouTube users access the application from mobile devices. The contents uploaded on YouTube come from different sources. An increasing number of individuals and media channels have the ability to upload and react to a varied range of media contents. Interactivity is another feature of YouTube, and it does not only ease social networking practices, but it also fosters the individual's perceptions of their environment. It is worth mentioning that YouTube is a perfect match for the social theory of learning. The YouTube platforms are social contexts with a lot of opportunities for learning. The use of YouTube as an instructional tool in language learning is investigated in many studies.

Alhamami (2013) is carried out for the purpose of a valid educational incorporation of YouTube. The use of YouTube for language learning is assessed against an evaluation list. Most specifically, the checklist comprises five evaluative criteria: "video characteristics", "attractiveness", "clarity", "reaction" and "content". These are the determinants of validity that ensure efficient use of YouTube as a means of instruction. The "video characteristics" of YouTube language learning relate to the correct display of the contents intended for language learning. "Attractiveness" is exclusive to the affect construct in language learning and how it manages to condition the acceptance of YouTube technology on the part of language learners. "Clarity" is a category of meanings that determine the accessibility of the language learning contents on YouTube. "Reaction" is specific the interactive environments of YouTube and the extent to which they allow the instructor to assist learners throughout their language learning. "Content" is related to the quality of the video design and how it manages to communicate detailed information about the uploaded contents on YouTube.

In parallel with what has been noted on the divide between technology and pedagogy in the YouTube tradition in language learning, Brook (2011) investigates the potential of YouTube in an English as Second Language (ESL) context. The YouTube experimentation is held on a population of 10 students who take part in an ESL programme for the purpose of gaining the linguistic, social and cultural competencies needed for integrating an American university. The experimentation is structured over a series of lessons to ensure the participants are assisted in the choice of a local culture topic, the design of a video-script and the fundamentals of video-sharing. Eventually, the findings of study corroborate the positive influence of YouTube in ESL learning contexts. YouTube is identified with the ability to yield highly interactive learning environments with ample opportunities for interaction. Besides the learner-learner interaction, the YouTube platform is found capable of activating unlimited channels of communication. Most importantly; the enabling attributes of YouTube translate into quantifiable proficiency skills on the part of learners who are given full control over the process of learning.

Indeed, educational YouTube is presented with a number of abilities that are likely to revitalise the language learning contexts. The various applications of YouTube in 
language learning converge towards fostering the quality of video contents to stimulate a wide range of interactivity on the part of learners. The realities mediated on YouTube are potentially advantageous to the contexts of language learning because they allow language learners to be functional in real-life situations where the outcomes of learning are easily converted to life-long competencies.

The social networking tradition in language learning is not exclusive to Facebook, WhatsApp and YouTube; still, these are among the most prominent social-networking platforms. They have rapidly evolved and expanded to attract the largest numbers of users and thereby forge identities of their own all over the globe. Many studies are conducted with the intent to inform on the reciprocity between language learning and social networking. Indeed, there is evidence of the legitimacy of social networking in the educational context as it perfectly synchronises with the basics of MALL. However, the educational use of social networking remains an immature orientation in language learning, in need of a lot research.

\section{GAME-BASED LEARNING}

Mobile gaming is already a legitimate extension of the fundamentals of mobile technology. The mobile gaming industry continues to penetrate new markets and generate substantial revenues. According to Statistica (2017), the net revenues of Google Play and Apple App Store for the last quarter of 2015 equalled 4.1 billion U.S dollars while the revenues of both companies in the same quarter of 2016 reached 7.4 billion U.S dollars. This accounts for a $78 \%$ growth over a one-year period. The far-reaching character of mobile gaming does not only impact the global smartphone market, but it redefines the common conceptions of social interaction. The language learning context is also impacted by the mobile game-based tradition in education. This is due to the social nature of gaming that is further enhanced by the features of technology and mobility. The influence of mobile gaming on language learning is consequential, but it needs to be theoretically based. This subsection exposes the potential of mobile gaming and the challenges educators need to undertake for maximum efficiency.

Mobile gaming offers many opportunities for educators to connect to the needs of a large population of language learners. In this respect, Sanderberg, Maris and de Geus (2011) reports on the advantages of the instructional use of mobile gaming in language learning. The enquiry uses a GPS-based game to extend the abilities of EFL students to learn vocabulary. In particular, the experimentation is conducted on three groups: one control group and two experimental groups. The control group is taught vocabulary in a conventional way. In both experimental groups, the participants are offered smart phones with a customised game-based application for learning vocabulary. Still, only the third group has permanent access to the smart phones outside the regular school hours. The findings from the study reveal the outperformance of the third group where access to smart phones is not controlled. The participants in the third group spent more time operating the vocabulary game in their smart phones, which demonstrates the susceptibility of mobile gaming to create the need for learning.

In parallel with what has been noted on the positive influence of mobile gaming on language learners' motivation, Perry (2015) departs from the addictive character of video games to optimise a "gamification" of language learning. The researcher manages to explore the offerings of quest-based learning. The study uses a mobile quest game, named Explorez [explore]. This mobile learning tool is presented as "a virtual narrative treasure hunt wherein the player is hired as the personal assistant to a famous French celebrity" (Perry, 2015, p. 1310). The application uses GPS technology to generate augmented reality environments where language learners interact and learn through the completion of a series of task based learning objectives. Most importantly, learners' multiple interactions on the virtual platform capitalise on the use of written, audio, and video contents to ensure learners obtain maximum practice in receptive and productive language skills. The findings of the study substantiate the merits of this innovative language learning tool. The legitimacy of Explorez does not only draw on the fun component in the language learning, but it also connects to the imperatives of accuracy.

There is evidence of the legitimacy of the game-based tradition in language learning. It is an innovative orientation in the language learning discourse with the ability to activate new modes of language acquisition. The conventional environments of language learning are reinvented and extended (Perry, 2015; Reinhardt \& Sykes, 2014; Thorne, Black, \& Sykes, 2009). In parallel, gamebased learning is identified with the ability to promote intrinsic motivation on the part of language learners (Sanderberg, Maris \& de Geus 2011). Language proficiency is a major theme in the multiple incorporations of mobile game-based learning. The augmented realities and interactive environments in mobile gaming enable quantifiable language proficiency skills. In this vein, Hwang, Shih, Ma, Shadiev and Chen (2016) corroborates the positive influence of mobile game-based language learning on students' listening and speaking skills. Hwang, Chen, Shadiev, Huang and Chen (2014) substantiates the 
advantages of using mobile-based situational learning as a means of fostering students' writing abilities. Indeed, the multiple incorporations of game-based learning are the basis of an innovate approach to language learning that is simultaneously true to the authenticity of real-life learning and committed to the determinants of language proficiency.

The concern with the incorporations of mobile gamebased language learning does not stem from the functionality of the instructional tool as much as it centres on its pedagogical dimension. The multiple incorporations of mobile technology in language learning contexts are confronted with the fundamentals of schooling. In this vein, Perry (2005)' "gamification" of language learning may have created optimal environments for language acquisition with maximum attention given to authenticity. Still, the divide between the institutionalised character of language learning and the innovative attributes of gamebased learning is not fully exposed. The two orientations are not necessarily inclusive of one another in the absence of a convenient theory and methodology of instruction. The challenge for the implementers is to contain the multiple affordances of mobile game-based language learning in an educational model that is true to the fundamentals of schooling in terms of authenticity and accuracy. The enhanced environments used for simulating real life situations for learning should not alienate the legitimate focus on language proficiency. In parallel, another challenge in optimising mobile game-based language learning concerns the ethical responsibilities of both educators and learners in the gaming environments. There is evidence of the positive impact of mobile gamebased learning on language learners' autonomy (Sanderberg, Maris \& de Geus 2011). Still, autonomous learning cannot alienate the teacher-centred approaches to language learning. The presence of a teacher is needed to assist language learners throughout a long process of reflective learning. This creates a situation where teachers must be fully aware of the attributes of the game-based environments used for language learning, which is not a simple thing to do (Becker, 2007).

Indeed, game-based learning is a promising trend in mobile learning. The potential of mobile gaming is identified with multiple educational affordances. The mobile game-based tradition in language learning translates into quantifiable gains for learners. The key features of the virtually enhanced environments of gamebased leaning are the authenticity and spontaneity of the processes of learning. Still, the educational incorporations of mobile gaming in language learning contexts must synchronise with an operational pedagogy.

\section{CONCLUSIONS}

A substantial body of research is conducted on the multiple incorporations of MALL. The extensions of mobile learning in the language learning discourse confirm the far-reaching character of mobile technology. SMSbased learning, educational podcasting, social networking and mobile gaming are distinct incarnations of MALL. They vary the means of implementation, but they serve the same purpose. They aspire to add more quality to education.

The MALL tradition in education is not without uncertainties (Morchid, 2019). The instructional use of mobile technology for language learning purposes must stem form a valid conceptual framework, with the ability to espouse the learning environments of MALL and the fundamentals of language learning. The fact is that MALL has not yet proved its worth in the institutionalised contexts of education. It strives for acceptance and recognition. The only way for MALL to impact schooling is to synchronise with a functional pedagogy that is simultaneously true to the needs of learners and the basics of institutionalised education.

The affordances of MALL are many and they exert a wide range of positive influences on the educational discourse. The challenge for researchers and educators is to understand and determine the factors that impact language learners' acceptance of MALL. Also, success implementations of MALL are not necessarily replicable. All incorporations of MALL must be true to the context of implementation.

\section{REFERENCES}

[1] Abdous, M. H., Camarena, M. M., \& Facer, B. R. (2009). MALL technology: Use of academic podcasting in the foreign language classroom. ReCALL, 21(01), 76-95.

[2] Aburezeq, I. M., \& Ishtaiwa, F. F. (2013). The impact of WhatsApp on interaction in an Arabic language teaching course. International Journal of Arts \& Sciences, 6(3), 165.

[3] Akbari, E., Pilot, A., \& Simons, P. R. J. (2015). Autonomy, competence, and relatedness in foreign language learning through Facebook. Computers in Human Behavior, 48, 126-134.

[4] Al Qasim, N., \& Al Fadda, H. (2013). From Call to Mall: The effectiveness of podcast on EFL higher education students' listening comprehension. English Language Teaching, 6(9), 30.

[5] Alhamami, M. (2013). Observation of YouTube language learning videos. Teaching English with Technology, (3), 317

[6] Becker, K. (2007). Digital game-based learning once removed: Teaching teachers. British Journal of Educational Technology, 38(3), 478-488. 
[7] Brook, J. (2011). The affordances of YouTube for language learning and teaching. Hawaii Pacific University TESOL Working Paper Series, 9(1), 2.

[8] Buga, R., Căpeneaţă, I., Chirasnel, C., \& Popa, A. (2014). Facebook in foreign language teaching-A tool to improve communication competences. Procedia-Social and Behavioral Sciences, 128, 93-98.

[9] Cavus, N., \& Ibrahim, D. (2009). M-Learning: An experiment in using SMS to support learning new English language words. British journal of educational technology, 40(1), 78-91.

[10] Facebook. (2017). Company info. Retrieved on April 01st, 2017, from http://newsroom.fb.com/company-info/

[11] Farangi, M. R., Nejadghanbar, H., Askary, F., \& Ghorbani, A. (2015). The Effects of Podcasting on EFL UpperIntermediate Learners' Speaking Skills. CALL---EJ, 16(2).

[12] Fattah, S. F. E. S. A. (2015). The Effectiveness of Using WhatsApp Messenger as One of Mobile Learning Techniques to Develop Students' Writing Skills. Journal of Education and Practice, 6(32), 115-127.

[13] Hwang, W. Y., Shih, T. K., Ma, Z. H., Shadiev, R., \& Chen, S. Y. (2016). Evaluating listening and speaking skills in a mobile game-based learning environment with situational contexts. Computer Assisted Language Learning, 29(4), 639-657.

[14] Kaplan, A. M., \& Haenlein, M. (2010). Users of the world, unite! The challenges and opportunities of Social Media. Business horizons, 53(1), 59-68.

[15] Kukulska-Hulme, A. (2009). Will mobile learning change language learning?. ReCALL, 21(02), 157-165.

[16] Kukulska-Hulme, A. (2012). Chapter One: Language Learning Defined by Time and Place: A Framework for Next Generation Designs. In Left to my own devices: Learner autonomy and mobile-assisted language learning. BRILL.

[17] Kukulska-Hulme, A., \& Shield, L. (2008). An overview of mobile assisted language learning: From content delivery to supported collaboration and interaction. ReCALL, 20(3), 271-289.

[18] Lantz-Andersson, A., Vigmo, S., \& Bowen, R. (2013). Crossing boundaries in Facebook: Students' framing of language learning activities as extended spaces. International Journal of Computer-Supported Collaborative Learning, 8(3), 293-312.

[19] Li, H. C. (2010). Using podcasts for learning English: perceptions of Hong Kong Secondary 6 ESL students. Début: the undergraduate journal of languages, linguistics and area studies, 78 .

[20] Morchid, N. (2019). The Determinants of Use and Acceptance of Mobile Assisted Language Learning: The Case of EFL Students in Morocco. Arab World English Journal (AWEJ) Special Issue on CALL, (5).

[21] Motiwalla, L. F. (2007). Mobile learning: A framework and evaluation. Computers \& education, 49(3), 581-596.

[22] Perry, B. (2015). Gamifying French Language Learning: a case study examining a quest-based, augmented reality mobile learning-tool. Procedia-Social and Behavioral Sciences, 174, 2308-2315.

[23] Plana, M. G. C., Torrano, P. G., \& Grova, M. E. (2012). SMS as a learning tool: An experimental study. The EUROCALL Review, 20(2), 33-47.

[24] Reinhardt, J., \& Sykes, J. (2014). Special issue commentary: Digital game and play activity in L2 teaching and learning. Language Learning \& Technology, 18(2), 28.

[25] Sandberg, J., Maris, M.,\& de Geus, K. (2011). Mobile English learning: An evidence-based study with fifth graders. Computers \& Education, 57, 1334-1347.

[26] Statistica. (2017). Mobile Gaming- Statistics \& Facts. Retrieved on April 28th , 2017, from: https://www.statista.com/topics/1906/mobile-gaming/

[27] Thorne, S. L., Black, R. W., \& Sykes, J. M. (2009). Second language use, socialization, and learning in Internet interest communities and online gaming. The modern language journal, 93(s1), 802-821.

[28] WhatsApp. (2017). About WhatsApp. Retrieved on April 09th , 2017, from https://www.whatsapp.com/about/

[29] Yang, J. (2013). Mobile assisted language learning: review of the recent applications of emerging mobile technologies. English Language Teaching, 6(7), 19.

[30] YouTube. (2017). YouTube Press. Retrieved on April 25th , 2017, from https://www.youtube.com/about/press/

[31] Zhang, H., Song, W., \& Burston, J. (2011). Reexamining the effectiveness of vocabulary learning via mobile phones. Turkish Online Journal of Educational Technology-TOJET, 10(3), 203-214. 